\title{
AVALIAÇÃO DA PRODUÇÃO DE BIOGÁS UTILIZANDO GLICEROL E RESÍDUOS DE RESTAURANTE COMO SUBTRATOS ORGÂNICOS
}

\author{
Patrícia Raquel Koch ${ }^{1}$, Maria Cristina de Almeida Silva²
}

\begin{abstract}
Resumo: A escassez dos combustíveis fósseis (petróleo, gás natural e carvão) é algo inevitável, sendo assim é necessária a busca por fontes energéticas alternativas, ou renováveis. A utilização de substrato orgânico na digestão anaeróbia para a produção de biogás vem se destacando, pois é obtida a partir de fonte renovável e pode ser utilizada para a produção de energia. Realizou-se um experimento de digestão anaeróbia com alimentações semanais dos substratos glicerol e resíduos de restaurante em reatores de 2 $\mathrm{L}$ de volume útil. No experimento, utilizou-se 1,2 L de inóculo com alimentação de $37,5 \mathrm{~mL}$ de ambos os substratos, esse experimento teve duração de 65 dias. Em relação ao volume de biogás gerado na comparação dos 2 substratos, o resíduo de restaurante produziu mais e seu percentual de metano foi superior ao encontrado no biodigestor com adição de glicerol.
\end{abstract}

Palavras-chave: Biogás. Quantificação do biogás. Comparação de resultados.

\section{EVALUATION OF BIOGAS PRODUCTION USING GLYCEROL AND RESTAURANT RESIDUES AS ORGANIC SUBTRACTS}

\begin{abstract}
The shortage of fossil fuels (oil, natural gas and coal) is inevitable, so it is necessary to search for alternative or renewable energy sources. The use of organic substrate in anaerobic digestion for the production of biogas has been highlighted, since it is obtained from a renewable source and can be used for the production of energy. An anaerobic digestion experiment was carried out with weekly feeds of the glycerol substrates and restaurant waste in $2 \mathrm{~L}$ reactors of useful volume. In the experiment, $1.2 \mathrm{~L}$ of inoculum was used, with feed of $37.5 \mathrm{~mL}$ of both substrates. This experiment lasted 65 days. In relation to the volume of biogas generated in the comparison of the two substrates, the restaurant residue produced more and its percentage of methane was higher than that found in the biodigester with addition of glycerol.
\end{abstract}

Keywords: Biogas. Quantification of biogas. Comparison of results.

1 Bacharel em Engenharia Química pelo Centro Universitário UNIVATES, Lajeado/RS. Os dados deste artigo são baseados na sua monografia de conclusão do Curso, defendida em dez/2016. patikoch@ universo.univates.br

2 Professora do Centro Universitário UNIVATES, Lajeado/RS. Doutora em Recursos Hídricos e Saneamento Ambiental, UFRGS. Orientadora do trabalho de Patrícia. maria.silva9@univates.br 


\section{INTRODUÇÃO}

A matriz energética mundial é composta, principalmente, por fontes não renováveis (petróleo, carvão e gás natural) (GUIMARÃES; GALVÃO, 2015). Dentre estas, a gasolina e o óleo diesel obtidos do petróleo constituem a base do setor de transportes quase na sua totalidade (CNI, 2012). A extração e a utilização da energia a partir da queima de combustíveis fósseis causam muitos problemas ambientais, pois se tem a geração de vários gases que estão diretamente relacionados às mudanças climáticas e à poluição atmosférica (RIFKIN, 2003).

Desta forma, a sociedade enfrenta um problema a ser solucionado em relação à matriz energética mundial, sendo que esse caminho apenas será alcançado quando o foco for o uso de energias alternativas (SILVA, 2013; KARLSSON et al., 2014).

Fontes alternativas são provenientes de recursos naturais que possuem a capacidade de regeneração, ou seja, são consideradas inesgotáveis e não prejudicam a natureza. Segundo a publicação do Ministério de Minas e Energia (MME) de dezembro de 2014, o Brasil ocupa a quarta posição no ranking de produção de energia por fontes renováveis e é considerado pioneiro mundial neste segmento de biocombustíveis (Agência Nacional de Petróleo, Gás Natural e Biocombustíveis - ANP, 2015). Entre os biocombustíveis, a biomassa vem se destacando, podendo ser uma alternativa de diversificação na matriz energética (BACKES, 2011).

Para que a biomassa seja utilizada como um biocombustível, é necessário que ela seja convertida de forma biológica, através da ação de microrganismos e enzimas que são responsáveis pela sua transformação a combustíveis gasosos (biogás e biohidrogênio) pelo processo denominado de digestão anaeróbia (LORA; VENTURINI, 2012).

Neste, ocorre a conversão da matéria orgânica biodegradável contida em efluentes líquidos e/ou resíduos sólidos à biogás através de 4 fases: hidrólise, acidogênese, acetogênese e a metanogênese (CHERNICHARO, 2007).

Alguns fatores, tanto químicos como físicos, são importantes por influenciar o crescimento microbiano e, consequentemente, a produção do biogás. Os fatores são: ausência de oxigênio, temperatura, alcalinidade e $\mathrm{pH}$, composição dos substratos e o tempo de detenção hidráulico (TDH) (SILVA, 2013; CASSINI, 2003). A composição do substrato tem relação direta com o processo utilizado para seu tratamento e a porcentagem dos gases presentes no biogás produzido (CORTEZ, LORA, GÓMEZ, 2008).

Este trabalho buscou a avaliação do potencial de produção de biogás através da utilização de dois resíduos, glicerina residual e resíduos orgânicos de restaurante, e lodo oriundo de reator anaeróbico como inoculo. Foi comparada a produção de biogás destes substratos e foi determinada a quantificação de cada resíduo. 


\section{METODOLOGIA}

O experimento e a análise para caracterização, tanto física como química, foram realizadas na Univates. No experimento, foram utilizados os reatores alocados na incubadora bacteriológica adaptada do Laboratório de Biorreatores, localizado prédio 20 do Tecnovates.

No experimento, foram testados os resíduos de restaurante (RR) e glicerol, na proporção total de $300 \mathrm{~g}$, divididas em 8 alíquotas para alimentações semanais. Foram utilizados reatores de vidro com volume total de $2 \mathrm{~L}$ e volume útil de 1,5 L.

\subsection{Substratos e inóculo}

Os RR são compostos por $28,6 \%$ de folhas verdes, $23,5 \%$ de cascas de vegetais e $47,9 \%$ de restos de comida. Os RR foram coletados em um restaurante localizado no prédio 9 da Univates.

Em seguida, os mesmos foram triturados, utilizando um liquidificador, e posteriormente misturados até que a amostra atingisse uma homogeneidade, conforme Figura 1.

Figura 1 - Trituração dos resíduos para alimentação dos reatores (a) e composição do $\mathrm{RR}$ (b)

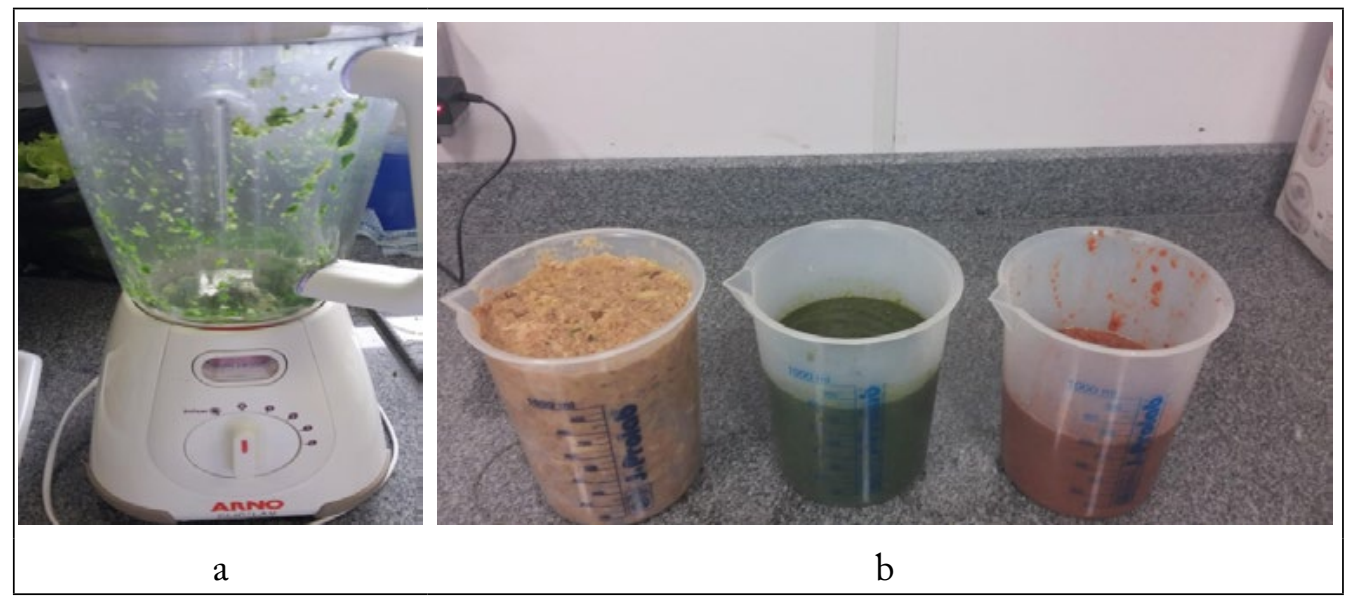

Fonte: Dos autores, 2016.

Para o experimento, pesou-se 24 alíquotas, de $37,5 \mathrm{~g}$ cada, em filme plástico. Destas, 21 foram congeladas para que fossem adicionadas durante 7 semanas nos respectivos 3 reatores destinados para o teste deste substrato. As 3 alíquotas restantes foram adicionadas na partida dos reatores. 
O glicerol foi proveniente da Associação dos Fumicultores do Brasil (AFUBRA), localizada no município de Santa Cruz do Sul/RS. Para a alimentação dos reatores com esse substrato, foi necessário aquecê-lo para sua sucção, utilizando uma seringa para a transferência.

O lodo anaeróbico oriundo do biodigestor de escala-piloto do Centro de Estudos de Biogás e Energias Renováveis (CEBER) foi utilizado como inoculo dos experimentos. $\mathrm{O}$ mesmo foi homogeneizado antes da sua adição nos reatores. $\mathrm{O}$ teste referência, ou branco, foi realizado somente com a adição do inoculo, a fim de verificar a sua contribuição para a produção de biogás. Antes da adição do inoculo e dos substratos aos reatores, a caracterização física e química dos mesmos foi realizada de forma individual.

\subsection{Descrição dos experimentos}

Foram utilizados 7 reatores (FIGURA 2), e um deles foi considerado como referência, em que foi adicionado apenas $1,5 \mathrm{~L}$ de inóculo, para avaliar a produção de biogás somente deste componente (branco). Nos outros 6 reatores, foram adicionados 1,2 L de lodo para avaliar os substratos RR e glicerol, cada um em triplicata. Os mesmos foram preenchidos com $300 \mathrm{~g}$ de substrato ao final do experimento, sendo esta quantidade necessária para completar o volume útil de cada reator (inóculo + substrato). Sendo assim, esta quantidade total foi dividida em alimentações semanais, de 37,5 g de cada de substrato, no período de 2 meses.

Figura 2 - Experimento encaminhado no laboratório de Biorreatores para a produção de biogás

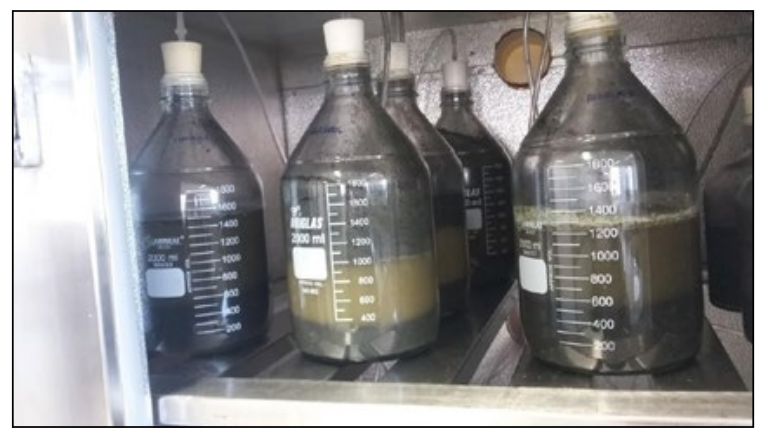

Fonte: Dos autores, 2016.

Como foi adotado o critério da constatação da não produção de gás para o término dos testes, os experimentos não foram encerrados no mesmo momento. Não foi verificada a produção de biogás nos reatores alimentados com glicerol e RR decorridos 29 e 64 dias de operação, respectivamente. Já o reator referência foi mantido por 49 dias. 


\subsection{Condições operacionais}

Todos os testes foram operados na faixa de temperatura mesofílica $\left(30-37^{\circ} \mathrm{C}\right)$, por esta ser considerada a ideal para o desenvolvimento dos microrganismos metanogênicos. Os reatores foram colocados em uma incubadora bacteriológica adaptada e foram conectados tubo em U.

O volume do biogás gerado foi determinado por um sistema automatizado, composto por um tubo de vidro em formato $\mathrm{U}$, sensor óptico, esfera de isopor e circuito eletrônico que registrou e armazenou a quantidade de biogás que passou pelo sistema, conforme pode ser visualizado na Figura 3 (CATANEO, 2015).

Figura 3 - Tubos em forma "U” - Medidor de vazão de gás

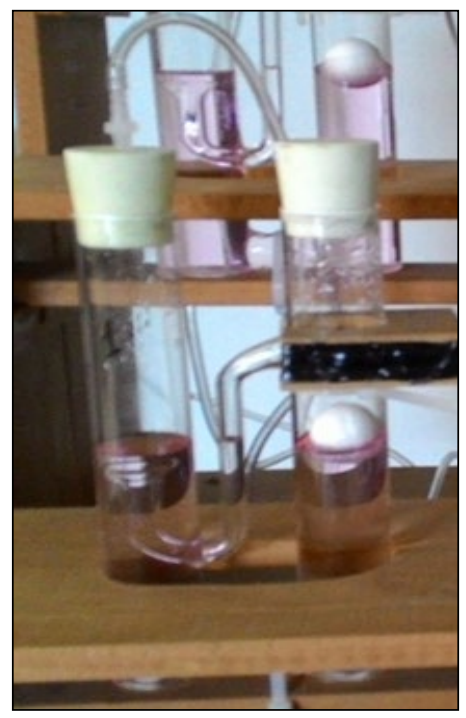

Fonte: Cataneo (2015).

O tubo em "U", Figura 3, tem seu princípio baseado no deslocamento de fluídos. Está conectado por uma mangueira ao reator onde se tem a produção de biogás. Este gás desloca o fluído nele contido para o outro tubo, enchendo assim o tubo em "U", aumentando o nível do outro tubo, fazendo com que a esfera passe pelo sensor óptico, que detecta o movimento e envia uma informação para um circuito eletrônico. O volume produzido foi definido pela lei dos gases ideais, que possui relação entre temperatura, pressão e volume de um gás, que é constante (CATANEO, 2015).

A quantificação do biogás gerado foi realizada no sensor portátil Advanced Gasmitter. Realizou-se a injeção diária de certa quantidade de amostra no sensor com auxílio de uma seringa. A verificação desse sensor é realizada mensalmente a partir da análise de uma mistura de padrões certificados, constituída por $\mathrm{CH}_{4}$ e $\mathrm{N}_{2}$. 


\subsection{Análises físicas e químicas}

A caracterização do efluente utilizado no experimento foi realizada a partir de análises físicas e químicas: demanda química de oxigênio (DQO), sólidos (totais, fixos e voláteis), $\mathrm{pH}$ e alcalinidade. Com relação à periodicidade das análises, as mesmas aconteceram no início e no final do experimento. As análises descritas foram realizadas conforme o Standard Methods for the Examination of Wastewater (APHA, 2005).

\section{DISCUSSÃO DE RESULTADOS}

Antes do início do experimento, foi realizada a caracterização física e química do inóculo e dos substratos, conforme mostrado na Tabela 1.

Tabela 1 - Resultados das médias das análises físicas e químicas com desvio padrão para o inóculo e os substratos utilizados nos experimentos

\begin{tabular}{c|c|c|c}
\hline Análise & Inóculo & Inóculo + RR & Inóculo + Glicerol \\
\hline $\begin{array}{l}\mathrm{DQO}(\mathrm{mg} \\
\left.\mathrm{O}_{2} / \mathrm{L}\right)\end{array}$ & $11.097,99 \pm 613,48$ & $60.999,60 \pm 3.214,46$ & $\begin{array}{c}1.065 .800,86 \\
\pm 72.751,63\end{array}$ \\
\hline $\begin{array}{c}\mathrm{Alcalinidade} \\
\left(\mathrm{mg} \mathrm{CaCO}_{3} / \mathrm{L}\right)\end{array}$ & $14.339,81 \pm 109,61$ & $14.980,58 \pm 255,77$ & $535.223,81 \pm 5.955,97$ \\
\hline $\mathrm{pH}$ & $5,90 \pm 0,01$ & $6,80 \pm 0,01$ & $6,93 \pm 0,09$ \\
\hline $\begin{array}{c}\text { Sólidos voláteis } \\
(\mathrm{SV})(\mathrm{mg} / \mathrm{L})\end{array}$ & $31.906,67 \pm 311,11$ & $219.306,67 \pm 20.160,62$ & $\begin{array}{c}1.016 .333,34 \pm \\
45.110,79\end{array}$ \\
\hline $\begin{array}{c}\text { Sólidos fixos } \\
(\mathrm{SF})(\mathrm{mg} / \mathrm{L})\end{array}$ & $14.640,00 \pm 183,30$ & $27.173,33 \pm 743,78$ & $40.220,00 \pm 7.591,08$ \\
\hline
\end{tabular}

Fonte: Dos autores, 2016.

O parâmetro DQO permite avaliar a quantidade de matéria orgânica propensa a ser oxidada por meios químicos existentes em uma amostra líquida ou sólida (RABELO, 2010). Este parâmetro pode ser relacionado à quantidade de matéria carbonácea disponível para ser convertida a biogás e metano. O valor obtido de DQO para o Inóculo + glicerol foi de 1.065.800,86 $\mathrm{mg} \mathrm{O}_{2} / \mathrm{L}$ com desvio padrão de 72.751,63 $\mathrm{mgO}_{2} / \mathrm{L}$. Para o Inóculo $+\mathrm{RR}$ obteve o valor de $60.999,60 \mathrm{mgO}_{2} / \mathrm{L}$ com desvio padrão de 3.214,46 $\mathrm{mgO}_{2} / \mathrm{L}$. E para o inóculo, referência, obteve-se o valor de 11.097,99 $\mathrm{mgO}_{2} / \mathrm{L}$ com desvio padrão de $613,48 \mathrm{mgO}_{2} / \mathrm{L}$.

APPLES (2008) destaca que o $\mathrm{pH}$ do sistema é controlado na fase líquida pela alcalinidade, funcionando como um tampão que evita as mudanças bruscas de pH (CHERNICHARO, 2007). Segundo METCALF; EDDY (2015) a faixa de alcalinidade deve estar entre 1000 e $5000 \mathrm{mg} / \mathrm{L}$ para que o processo de digestão anaeróbica ocorra dentro da sua normalidade. Sendo assim, a partir da análise dos dados da Tabela 1, verifica-se que tanto o inóculo como os substratos apresentaram alcalinidade acima da faixa considerada ideal. 
Conforme Ogejo e $\mathrm{Li}$ (2010), a faixa de $\mathrm{pH}$ ideal é 6,0 a 8,0. No processo de biodigestão anaeróbia, inicialmente ocorre a formação de ácido orgânico que poderá reduzir o $\mathrm{pH}$, mas com a transformação dos ácidos em produtos gasosos pelas bactérias metanogênicas, o $\mathrm{pH}$ retorna a um nível próximo do neutro. Em relação aos valores de $\mathrm{pH}$ da Tabela 1, quando comparados à faixa considerada ideal pelos autores supracitados, os substratos apresentaram valores de $\mathrm{pH}$ adequados. Os valores do $\mathrm{pH}$ inoculo mostraram-se abaixo do limite estabelecido, mas mesmo assim, isso não inibiu a produção de $\mathrm{CH}_{4}$, pois no experimento realizado, o reator de referência produziu biogás.

A fração orgânica presente no inóculo e nos substratos pode ser determinada através da análise de sólidos voláteis (SV), sendo também relacionada ao potencial de produção de biogás. Quanto maior o valor de SV, maior será a produção de metano na digestão anaeróbica (PESSUTI; 2015). Sendo assim, os valores apresentados na Tabela 1 indicam que ambos os substratos são aptos a produzir biogás, já que o glicerol e RR apresentaram SV de $984.426,67 \mathrm{mg} / \mathrm{L}$ e $187.400,00 \mathrm{mg} / \mathrm{L}$, respectivamente.

Ressalta-se que, nos reatores alimentados com glicerol, a produção de gás foi encerrada antes dos demais reatores utilizados em conjunto para a execução do experimento. A partir da análise do $\mathrm{pH}$ do meio reacional pós-teste, dos 3 reatores empregados, verificou-se que o mesmo estava acidificado, conforme mostrado na Tabela 2.

Tabela 2 - Resultados das médias das análises físicas e químicas com desvio padrão dos reatores ao final do $1^{\circ}$ experimento

\begin{tabular}{c|c|c|c}
\hline Análise & Inóculo & Inóculo + RR & Inóculo + Glicerol \\
\hline DQO $\left(\mathrm{mg} \mathrm{O}_{2} / \mathrm{L}\right)$ & $24.082,57 \pm 4865,41$ & $16.055,51 \pm 3.243,61$ & $9.056,24 \pm 3.039,58$ \\
\hline $\begin{array}{c}\text { Alcalinidade } \\
\left(\mathrm{mg} \mathrm{CaCO}_{3} / \mathrm{L}\right)\end{array}$ & $17.672,85 \pm 0,00$ & $18.913,05 \pm 146,16$ & $3.255,53 \pm 297,75$ \\
\hline $\mathrm{pH}$ & $8,01 \pm 0,01$ & $8,37 \pm 0,05$ & $5,67 \pm 0,15$ \\
\hline $\mathrm{SV}(\mathrm{mg} / \mathrm{L})$ & $40.200,00 \pm 16.037,18$ & $20.240,00 \pm 8984,51$ & $70.800,00 \pm 36.725,50$ \\
\hline $\mathrm{SF}(\mathrm{mg} / \mathrm{L})$ & $14.180,00 \pm 537,40$ & $12.840,00 \pm 509,12$ & $17.880,00 \pm 4.457,57$ \\
\hline
\end{tabular}

Fonte: Dos autores, 2016.

De acordo com Aquino e Chernicharo (2005), a metanogênese somente acontecerá quando o $\mathrm{pH}$ do meio estiver próximo ao neutro. Ácidos orgânicos voláteis são produzidos durante a decomposição da matéria orgânica, na etapa acidogênica da digestão anaeróbia. Caso haja sobrecarga orgânica, ou seja, adição de elevada concentração de substrato, é possível o desencadeamento de uma instabilidade no reator. Isso ocorre porque a taxa de remoção de ácidos voláteis, através da metanogênese, não acompanha a taxa de produção dos mesmos na acidogênese. Como consequência, 
a produção líquida de ácido resulta numa tendência de diminuição do valor do $\mathrm{pH}$, acarretando redução adicional da atividade metanogênica (FERNANDES, 2017).

A partir dos valores da Tabela 2, realizou-se um comparativo dos resultados obtidos no fim e no início dos experimentos. Os valores dos parâmetros referentes aos substratos, quase que em sua totalidade, apresentaram redução. Como já citado, esses parâmetros apresentam relação direta com a produção de biogás. Já em relação aos resultados do inóculo, apenas os sólidos fixos (SF) apresentaram redução de 4,14\%, os demais valores obtidos todos apresentaram resultados maiores que os iniciais. Esses valores podem ter sofrido um acréscimo, pois trata-se de um lodo mais antigo de um biodigestor, logo há a possibilidade do processo de digestão anaeróbica já estar ocorrendo. Ele apenas foi utilizado como um inóculo para se ter as bactérias iniciais no intuito do processo de digestão anaeróbica ocorrer de forma mais fácil e um pouco mais rápida.

Nos reatores alimentados com glicerol, além da redução do $\mathrm{pH}$, como comentado anteriormente, também foi constatada a redução de 99,15\% de DQO. Com relação a alcalinidade, constatou-se redução de seu valor em 99,39\%. Acredita-se que esta diminuição seja decorrente da reação da alcalinidade com os ácidos formados. De acordo com Chernicharo (2007), a alcalinidade evita que mudanças bruscas de $\mathrm{pH}$ ocorram em sistemas biológicos, sendo consumida para que os ácidos orgânicos, formados na etapa acidogênica, não acarretem instabilidade operacional nos reatores anaeróbios. Mesmo que essa alcalinidade representou uma redução de quase 100\%, a mesma não foi suficiente para manter o $\mathrm{pH}$ do meio na faixa ótima para o desenvolvimento bacteriano.

Já os sólidos voláteis (SV) apresentaram redução em torno de 93,03\%, e os SF obtiveram uma diminuição de 55,52\%. A diminuição dos valores de DQO e sólidos são esperados em digestão anaeróbia, pois os mesmos representam o consumo da fração orgânica, contida no substrato e inoculo, para produção de biogás (LOVATO et al, 2015).

Quando testados os RR, foi verificada redução 73,68\% nos valores de DQO, $90,77 \%$ nos resultados dos SV e também de $52,75 \%$ nos SF, que podem ser relacionados à produção de gás. Com relação a alcalinidade ocorreu um acréscimo de $26,25 \%$. Esse valor pode ter aumentado, principalmente, pela degradação da matéria orgânica a partir da evolução do processo de digestão anaeróbica.

De acordo com Metcalf \& Eddy (2015), a alcalinidade pode ser produzida em reatores anaeróbios a partir da hidrólise de proteínas e de aminoácidos para produção de amônia, que reage com dióxido de carbono $\left(\mathrm{CO}_{2}\right)$ e água $\left(\mathrm{H}_{2} \mathrm{O}\right)$. Sendo assim, o resíduo de restaurante é propenso a apresentar estas substâncias em sua composição, o que não ocorre com o glicerol empregado. Isto corrobora o aumento de alcalinidade constatado somente no meio reacional oriundo dos reatores alimentados com RR.

O experimento teve duração distinta para cada substrato utilizado, em função da produção de biogás observada em cada um. Não foi verificada a produção de biogás 
nos reatores alimentados com glicerol e RR decorridos 29 e 64 dias de operação, respectivamente. Já o reator referência foi mantido por 49 dias.

A produção de biogás do experimento, em volume, bem como seus respectivos desvios, e percentuais de $\mathrm{CH}_{4}$, pode ser visualizada na Tabela 3 .

Tabela 3 - Volume total (L) e porcentagem média (\%) de biogás produzido nos reatores do experimento 1

\begin{tabular}{c|c|c|c}
\hline Reator & Volume de biogás $(\mathrm{L})$ & $\% \mathrm{CH}_{4}$ & Volume de $\mathrm{CH}_{4}(\mathrm{~L})$ \\
\hline Inóculo & 7,02 & 57,37 & 4,02 \\
\hline RR & $44,42 \pm 3,26$ & 58,19 & $25,85 \pm 1,90$ \\
\hline Glicerol & $16,86 \pm 2,58$ & 27,09 & $4,57 \pm 0,70$ \\
\hline
\end{tabular}

Fonte: Dos autores, 2016.

Para o inóculo, o desvio padrão não foi calculado por apenas ser encaminhado em uma via. Pode-se constatar considerável produção de biogás apenas deste contribuinte, com volume de cerca de $7 \mathrm{~L}$ e teor de $\mathrm{CH}_{4}$ de $57,37 \%$.

Nos demais reatores observou-se que a alimentação com ambos os substratos contribuiu para elevar o potencial de produção de biogás e metano nos experimentos, nas condições testadas. Verificou-se que o RR apresentou maior produção de biogás, tanto em relação ao volume como a porcentagem de $\mathrm{CH}_{4}$, do que o glicerol. Os RR foram adicionados na mesma quantidade do que o glicerol, embora resultassem em concentrações distintas de alimentação. A elevada carga orgânica intrínseca do glicerol pode ter favorecido um desequilíbrio nos reatores, que reduziu ou inibiu a atuação as bactérias metanogênicas para a produção do biogás (MACHADO et al., 2011).

Silva (2009) testou o potencial energético dos resíduos sólidos orgânicos provenientes de uma central de abastecimento de alimentos em reator anaeróbio de escala laboratorial, na quantificação obteve uma porcentagem de $61,5 \%$ de metano no biogás.

Kretzer, Nagaoka, Moreira, Rigoni, Moraes e Bauer (2016) utilizaram resíduos provenientes do Restaurante Universitário (RU) do Centro de Ciências Agrárias para abastecer os biodigestores. Foram utilizados 4 tipos de resíduos, T1: arroz, T2: beterraba + alface, T3: feijão e T4: arroz+beterraba+alface+feijão. Os biodigestores foram alimentados com $500 \mathrm{~g}$ de resíduo, $1000 \mathrm{~g}$ de água e $150 \mathrm{~g}$ de inóculo (esterco bovino da etapa final de biodigestão). A quantificação do biogás foi realizada a partir de um gasômetro e os digestores T2 e T4 não produziram biogás. Já a produção do T1 e T3 foi de 20 dias. A produção do T3 foi maior produção (1,48 L) quando comparado ao $\mathrm{T} 1$ que produziu $1,25 \mathrm{~L}$. 
Mafaciolli (2012) realizou adições de glicerina em dejetos de aves em 3 percentuais diferentes: $3 \%, 6 \%$ e $9 \%$. Com relação ao volume de biogás, o que mais produziu foi o de $9 \%$ que totalizou um volume de $16,88 \mathrm{~L}$. No biodigestor com adição de $3 \%$ e $6 \%$ produziram respectivamente, 7,68 L e 12,50 L. Com relação ao percentual de metano, o acréscimo de $3 \%$ foi o que apresentou o melhor índice, se obteve valores de 45 a $68 \%$.

Konrad et al. (2010) realizaram um estudo com amostras de lodo de estação de tratamento, acrescentando os percentuais de 3 e $6 \%$ de glicerina, em relação ao volume total do reator. Neste estudo, o que obteve a maior produção de metano no biogás foi o de $3 \%$, alcançando $72 \%$ e a produção total foi de $12,92 \mathrm{~L}$. Porém para fins energéticos o valor com adições de $6 \%$ também foram considerados satisfatórios, pois se gerou 5,8 L de biogás com um percentual de $61 \%$ de metano.

Realizando uma comparação com o volume de gás gerado pelo experimento, o glicerol apresentou uma elevada produção quando comparado aos estudos de Konrad et al. (2010) e Mafaciolli (2012), porém o percentual de metano encontrado (27,2\%) foi inferior aos estudos que obtiveram os seguintes percentuais $72 \%$ e 45 a $68 \%$, respectivamente.

Com relação à utilização de RR na produção de biogás, o volume gerado é superior ao glicerol. E na comparação do percentual de metano obtido com o estudo de Silva (2009) se pode afirmar que são semelhantes, pois a variação obtida foi de 5,38\% de metano.

\section{CONCLUSÃO}

Concluiu-se que nos experimentos onde foi utilizado o RR com substrato na alimentação dos reatores, obteve-se uma maior produção de biogás a comparar com os reatores que se adicionou o glicerol. Essa menor produção de biogás dos reatores de glicerol pode ter ocorrido devido ao substrato ser composto por uma elevada DQO, como pode ser verificado nas análises físicas e químicas. Essa elevada concentração, quando é submetida em processos de digestão anaeróbica, pode influenciar o processo de forma negativa reduzindo o $\mathrm{pH}$ do meio, o qual tem uma ligação com as bactérias metanogências, acarretando a sua inibição ou redução diminuindo assim a produção de biogás.

$\mathrm{Na}$ comparação dos dois substratos, os reatores com a adição de RR produziram um volume médio de 44,42 $\mathrm{L}$ e os reatores com alimentações semanais de glicerol a produção de biogás foi de 16,86 L. Além disso, os percentuais obtidos de metano no experimento foram diferentes: para o glicerol o percentual encontrado foi de 27,09\% e nos biodigestores com alimentação de RR se obteve um percentual de 57,09\% de metano. Para otimizar a produção de glicerol é necessária uma diluição do resíduo, pois possui uma elevada carga na qual desestabiliza o sistema quando as bactérias iniciam a conversão dos ácidos para posterior transformação em metano. 
Sendo assim, a biodigestão anaeróbia é uma solução ambiental rentável e sustentável, pois se pode utilizar tanto resíduos orgânicos como também resíduos industriais para a produção de biogás e posterior purificação para utilização deste gás para os mais diversos fins.

\section{REFERÊNCIAS}

ANP, AGÊNCIA NACIONAL DE PETRÓLEO, GÁS NATURAL E BIOCOMBUSTÍVEIS. Biocombustíveis. 2015. Disponível em: <http://www.anp.gov. br/?id=470>. Acesso em: 26 mar. 2016.

APHA, AMERICAN PUBLIC HEALTH ASSOCIATHION. Standard methods for the examination of wastewater. 20. ed. New York, USA: APHA, 2005.

AQUINO, S.F.; CHERNICHARO, C.A.L. Acúmulo de ácidos graxos voláteis (AGV) em reatores anaeróbios sob estresse: causas e estratégias de controle. Revista de Engenharia Sanitária e Ambiental. 10: 152- 161, 2005.

BACKES, G. M. Avaliação do processo de digestão anaeróbica na geração de energia a partir de dejetos suínos e bovinos de leite com suplementação de glicerina residual bruta oriunda da produção de biodiesel. 2011. Dissertação (Mestrado em Ambiente e Desenvolvimento), Centro Universitário Univates, Lajeado - RS, 2011.

CATANEO, I. Comparativo do potencial de produção de metano utilizando glicerol e sacarose como substrato orgânico, em reatores operados de forma descontínua alimentada. Monografia de conclusão do curso de Engenharia Ambiental. Lajeado - RS, 2015.

CASSINI, S. T. Digestão de resíduos sólidos orgânicos e aproveitamento do biogás. Cap. 2 e 4. Rio de Janeiro: Projeto PROSAB, 2003.

CHERNICHARO, C. A. de L. Reatores anaeróbios. 2. Ed. Belo Horizonte, MG:

Departamento de Engenharia Sanitária e Ambiental - UFMG, 1997.

CNI, Confederação Nacional da Indústria. A contribuição do setor brasileiro de petróleo, gás e biocombustíveis para o desenvolvimento sustentável no país Conferência Rio+20. 2012. Disponível em: <http://arquivos.portaldaindustria.com.br/app/conteudo_18/2013/09/23 /4970/20131003104228715851e.pdf.> Acesso em: 14 mai. 2016.

CORTEZ, L. A. B.; LORA, E. E. S.; GÓMEZ, E. O. Biomassa para energia. São Paulo: Ed. Unicamp, 2008.

FERNANDES, C. (2017). Digestão Anaeróbia. Disponível em: <http://www.dec.ufcg.edu. br/saneamento/DigeAnae.html> Acesso em: 1 jun. 2017.

GUIMARÃES, C. M. M.; GALVÃO, V. Análise da rede de colaboração científica sobre biogás. Perspectivas em ciência da informação, v.20 n.2, 2015. Disponível em: <http:// portaldeperiodicos.eci.ufmg.br/index.php/pci/article/view/2305> Acesso em: 29 abr. 2016. 
KARLSSON, T.; KONRAD, O.; LUMI, M.; SCHMEIER, N. P.; MARDER, M.; CASARIL, C. E.; KOCH, F. F.; PEDROSO, A. G. Manual básico do biogás. Lajeado RS: Univates, 2014.

KRETZER, S. G.; NAGAOKA, A.K.; MOREIRA, T. E.; RIGONI, I. L.; MORAES, G.; BAUER F. C. Produção de biogás com diferentes resíduos orgânicos de restaurante universitário. Revista Brasileira de Energias Renováveis. v.5, n.4, p.551-565, 2016.

LOVATO, G.; MONCAYO BRAVO, I. S.; RATUSZNEI, S. M.; RODRIGUES, J. A. D.; ZAIAT, M. The effect of organic load and feed strategy on biohydrogen production in an AnSBBR treating glycerin-based wastewater. Journal of Environmental Management, v. 154 , p. $128-137,2015$.

MACHADO, F. S.; PEREIRA, L. G. R.; JÚNIOR, R. G.; LOPES, F. C. F.; CHAVES, A. V.; CAMPOS, M. M.; MORENZ, M. J. F. Emissão de metano na pecuária: Conceitos, métodos de avaliação e estratégias de mitigação. Juiz de Fora, MG: Embrapa Gado de Leite, 2011.

MADIGAN, M. T.; MARTINKO, J. M.; PARKER, J. Microbiologia de BROCK. 10. ed. São Paulo: Prentice Hall, 2014. Disponível em: <http://univates.bv3.digitalpages.com.br/ users/publications/9788587918512/pages/141> Acesso em: 12 abr. 2016

METCALF, L.; EDDY, H. P. Tratamento de efluentes e recuperação de recursos. 5a ed., McGraw Hill Brasil, 2008 p., 2015.

OGEJO, J. A.; LI, L.. Enhancing biomethane production from flush dairy manure with turkey processing wastewater. Applied Energy, p.10,2010.

PESSUTI, C. A. A.; HERMES, E.; ZENATTI, D. C.; SILVA, R. P. da. Remoção de sólidos e produção de metanona digestão anaeróbia de efluente de processamento de mandioca. Revista Brasileira de Energias Renováveis, v.4, p.110- 116, 2015.

SILVA, M. C. de A. Avaliação do regime operacional e da estabilidade microbiana no processo de fermentação anaeróbia para a produção de hidrogênio e ácidos graxos voláteis. Porto Alegre, RS: Qualificação de doutorado, UFRGS, 2013. Não publicado.

SILVA, W.R. Estudo Cinético do Processo de Digestão Anaeróbia de Resíduos Sólidos Vegetais. Tese de Doutorado. Universidade Federal da Paraíba. João Pessoa/PB, 2009. 